\title{
Análise de gênero discursivo na perspectiva dialógica do Círculo de Bakhtin: subsídios teóricos e aplicados
}

\author{
Valfrido da Silva Nunes* \\ Maria Inez Matoso Silveira**
}

\section{Resumo}

Este artigo versa sobre a noção de gêneros discursivos, enfatizando seus aspectos constitutivos (sociais e verbais). Discute de que maneira esses aspectos funcionam em um gênero típico da esfera administrativa estatal: o memorando. As bases teóricas do trabalho ancoram-se principalmente nos estudos dialógicos da linguagem, tendo em vista as contribuições do Círculo de Bakhtin (1976; 2003; 2009; 2013; 2014). Metodologicamente, trata-se de uma análise de corpus, em que se faz uma apreciação de um exemplar do memorando. Os resultados evidenciam a complexidade do funcionamento discursivo do gênero, a sua tendência à estabilidade e as marcas da formalidade e da objetividade.

Palavras-chave: Gêneros do discurso; Esfera administrativa; Memorando

\begin{abstract}
This article deals with the notion of genres, emphasizing its constituent aspects (social and verbal). Discusses how these features work in a typical genre of state administrative level: the memo. The theoretical bases of work anchored mainly on dialogical studies of language, in view of the contributions of the Circle of Bakhtin (1976; 2003; 2009; 2013; 2014). Methodologically, it is a corpus analysis, from which to make an assessment of a copy of the memo. The results show the complexity of the discursive functioning of the genre, its tendency to stability and trademarks of formality and objectivity.
\end{abstract}

Keywords: Discourse genres; Administrative level; Memo

\section{Introdução}

Partindo do princípio de que o conceito de gênero hoje tem se tornado objeto de múltiplas reconceituações, em virtude da amplitude que tem tomado e das diferentes perspectivas teóricas existentes, o presente artigo tece algumas considerações acerca da

\footnotetext{
* Doutorando em Linguística. Universidade Federal de Alagoas (UFAL). Faculdade de Letras (FALE). Programa de Pós-graduação em Letras e Linguística (PPGLL). Maceió. Alagoas. Brasil. E-mail: fridoval@hotmail.com.

** Doutora em Linguística. Universidade Federal de Alagoas (UFAL). Faculdade de Letras (FALE). Programa de Pós-graduação em Letras e Linguística (PPGLL). Maceió. Alagoas. Brasil. E-mail: mimatoso@uol.com.br.

Revista Leitura V.1 no 55 - jan/jun 2015 - Número temático: Estudos em perspectivas dialógicas. Análise de gênero discursivo na perspectiva dialógica do Círculo de Bakhtin: subsídios teóricos e aplicados. Valfrido da Silva Nunes e Maria Inez Matoso Silveira. - p. $129-144$. 
noção de gênero discursivo, especificamente à luz da teoria dialógica de Bakhtin e seu Círculo. Desse ponto de vista, objetiva-se verificar o funcionamento do gênero memorando na esfera burocrática estatal, observando não só os aspectos sociais que o engendram, mas também aqueles que dizem respeito à sua estrutura composicional e ao seu estilo verbal. Do ponto de vista teórico-epistemológico, este artigo filia-se aos estudos dialógicos do discurso, abordagem filosófica postulada pelo chamado Círculo de Bakhtin (VOLOSHINOV \& BAKHTIN, 1976; BAKHTIN, 2003; BAKHTIN \& VOLOCHÍNOV, 2009; BAKHTIN, 2013; BAKHTIN, 2014), que têm gerado trabalhos profícuos, em diferentes áreas do conhecimento, inclusive no mundo ocidental, e que vem crescendo no Brasil com repercussão significativa no ensino e na aprendizagem de línguas.

A metodologia insere-se no paradigma da pesquisa qualitativa, a partir da análise de corpus, constituída de um exemplar do gênero memorando, colhido em uma instituição pública de ensino, pesquisa e extensão. Embora saibamos que o exemplar em análise não dê conta, de forma mais ampla, do funcionamento discursivo do memorando em sua relação com as atividades humanas e com os sistemas de gêneros que organizam as práticas de escrita no mundo do trabalho, propomos lançar o gérmen para estudos ulteriores. A organização deste artigo contempla uma seção teórica e outra analítica, que dialogam entre si. Na primeira, apresentamos os fundamentos teóricos com base em algumas categorias bakhtinianas que iluminam as nossas análises; na segunda, fazemos uma análise do gênero em tela, a partir de um olhar bidirecional e dialético que busca observar tanto os aspectos de ordem social quanto os de ordem verbal.

\section{Alguns conceitos fundamentais da teoria bakhtiniana}

Apresentamos nesta seção alguns conceitos-chave da teoria bakhtiniana, uma vez que não concebemos os gêneros discursivos dissociados das múltiplas esferas da atividade humana, bem como não conseguimos desvinculá-los da noção de língua/linguagem preconizada pelo Círculo.

\section{A concepção de língua/linguagem}


Primeiramente, é justo dizer que a concepção de língua/linguagem postulada pelo Círculo é um dos grandes argumentos que sustentam a coerência de suas obras. Elas não se contradizem; ao contrário, seja o próprio Bakhtin, seja Volochínov, seja Medvedev que assinem as produções do Círculo, a crítica ao formalismo e a defesa de uma abordagem sociológica (da arte, da linguística, da literatura, da psicologia etc.) estão sempre presentes de forma problematizadora. A bem da verdade, Bakhtin \& Volochínov (2009) rechaçam contundentemente o que chamaram de objetivismo abstrato e subjetivismo idealista/individualista. Para eles, enquanto esta última corrente toma a língua como criação individual, aquela primeira tendência a vê como um sistema de formas abstratas. No primeiro caso, há uma onipotência do indivíduo e, no segundo, um poder absoluto da língua como tesouro depositado na mente dos falantes. Os autores ainda afirmam que, no plano literário, o objetivismo abstrato relaciona-se com o Realismo (princípios da objetividade, racionalidade e universalidade), enquanto o subjetivismo idealista alinha-se ao Romantismo (princípios da subjetividade, expressividade e do egocentrismo).

A posição dos autores é a de negar essa dupla orientação do pensamento filosófico-linguístico, vistas como ficção, propondo uma terceira concepção de língua/linguagem. Como afirmamos em outro trabalho (NUNES, 2010, p. 1808), "sob a influência de uma filosofia de base marxista, o mestre russo trata os fenômenos linguísticos do ponto de vista sociológico, considerando, sobretudo, os valores ideológicos que perpassam a língua(gem), a qual constrói a realidade e é constituída por ela.” Essa guinada da língua-sistema para a língua-discurso é retomada em Bakhtin (2013) que, reconhecendo as limitações da linguística formalista de sua época, propõe o que ele chama de translinguística ou metalinguística, antecipando o que hoje conhecemos como estudos do discurso. No dizer do autor, devemos tomar a língua "não como um sistema de categorias gramaticais abstratas, mas como uma língua ideologicamente saturada, como uma concepção de mundo, e até como uma opinião concreta que garante um maximum de compreensão mútua, em todas as esferas da vida ideológica" (BAKHTIN, 2014, p. 81).

Para o filósofo soviético, é primordial pensar a língua "como fenômeno integral concreto", como língua viva, articulada às práticas sociais, o que instaura o seu princípio dialógico, pois “é precisamente essa comunicação dialógica que constitui o verdadeiro campo da vida da linguagem.” (BAKHTIN, 2013, p. 209). Nesse sentido, 
não se trata de uma língua inerte, como um "arco-íris imóvel", mas de uma língua que não só reflete como também refrata a realidade, dada a natureza ideológica dos signos que a compõem (BAKHTIN, 2009).

Do ponto de vista bakhtiniano, o sistema linguístico existe, porém não é autônomo nem onipotente. Estudá-lo de forma isolada seria lidar com uma "línguamorta-estrangeira”, daí a necessidade de se tomar a língua em funcionamento, por meio dos gêneros, nas várias esferas da vida ideológica, pois só aí é possível apreendermos a sua dimensão axiológica. Essa posição é corroborada por Bakhtin (2014, p. 82), quando, apropriando-se mais uma vez de termos da Física, afirma que "ao lado das forças centrípetas caminha o trabalho contínuo das forças centrífugas da língua, ao lado da centralização verbo-ideológica e da união caminham ininterruptos os processos de descentralização e desunificação." (BAKHTIN, 2014, p. 82). Parafraseando o mestre soviético, já havíamos afirmado (NUNES, 2012, p. 23) que "as forças centrípetas concernem ao que é estático, ao passo que as forças centrífugas tendem para a inovação, para a dinâmica da língua." Considerando que essas forças não são dicotômicas, posto que se cruzam no momento da enunciação, entendemos que o sistema linguístico é uma força centrípeta, à medida que as variações constituir-se-iam em forças centrífugas.

Em suma, há de se convir que, para o Círculo de Bakhtin, "a língua constitui um processo de evolução ininterrupto, que se realiza através da interação verbal social dos locutores" (BAKHTIN/VOLOCHÍNOV, 2009, p. 131-132), em cujo âmago subjaz o dialogismo, que dá vida à língua, uma vez que "a orientação dialógica é naturalmente um fenômeno próprio a todo o discurso.” (BAKHTIN, 2014, p. 88).

\section{A concepção de esfera discursiva}

"Todos os diversos campos da atividade humana estão ligados ao uso da linguagem" (BAKHTIN, 2003, p. 261). É assim que se inicia o seminal ensaio, assinado pelo filósofo russo, intitulado "Os gêneros do discurso", o qual se constitui como o esboço prévio de uma obra não realizada, já que, nos planos de Bakhtin, havia a intenção de escrever um livro especificamente sobre esse assunto (BAKHTIN, 2003, p. 446-447). De qualquer maneira, convém ressaltar que, na citação acima, o mestre russo faz uma associação exitosa entre as práticas linguageiras e os campos da atividade humana. Dito de outra forma, os gêneros do discurso mantêm uma relação intrínseca 
com as diferentes instâncias da vida social, quais sejam: administrativa, cotidiana, militar, religiosa, política, dentre muitas outras.

Assim sendo, ressaltamos que a vida social organiza-se em múltiplas esferas, com seus repertórios próprios de gêneros, muito embora as fronteiras entre essas esferas sejam um tanto tênues, já que não são dicotômicas, ao mesmo tempo em que os interlocutores no processo de interação discursiva não se prendem tão somente a uma esfera específica. A bem dizer, os sujeitos transitam dialogicamente entre esses campos heterogêneos da vida social. Os múltiplos papéis sociais ocupados por um único sujeito no mundo da vida ilustram essa movência entre as esferas.

A nosso ver, essa noção de esfera discursiva proposta pelo Círculo revigora o conceito de gênero do discurso, pois é a partir desse olhar que os gêneros passam a ser vistos em sua relação intrínseca com as atividades sociais mediadas pela linguagem. Em outros termos, gêneros (orais e escritos) só existem porque existem necessidades comunicativas específicas, socialmente tipificadas, dada à sua natureza recorrente. Por exemplo, na esfera cotidiana, o gênero ticket de estacionamento de um shopping center emerge da necessidade de se fazer um rigoroso controle de quem entra com veículos e de se cobrar pelo uso daquele local por determinado período de tempo. Não é à toa que esse gênero contém dados que refletem essa necessidade: local, data, hora, código de barras, sequência numérica e, às vezes, observações como: "Antes de sair, validar no caixa de pagamento. Não deixe no veículo."

No nosso entendimento, a esfera discursiva também funciona como um critério definidor dos gêneros, pois, a título de ilustração, não podemos dizer que o resumo acadêmico (esfera acadêmica/científica) é o mesmo que resumo de novela (esfera do lazer/entretenimento), embora ambos tenham como propósito condensar as ideias centrais mínimas do texto-base. Indubitavelmente, as condições de interação são diferentes, o que contribui para a constituição de gêneros diferentes, visto que a relação entre as esferas comunicativas e os gêneros dá-se também pela dimensão cronotópica destes, pois, efetivamente, os gêneros são localizados no tempo (sua historicidade) e no espaço (seu campo predominante de existência, para além do locus físico). Como afirmam Bakhtin \& Volochínov (2009, p. 33), “cada campo de criatividade ideológica tem seu próprio modo de orientação para a realidade e refrata a realidade à sua própria maneira. Cada campo dispõe de sua própria função no conjunto da vida social”. É com 
essa visão que analisaremos o gênero memorando em sua relação intrínseca com a esfera burocrática estatal.

\section{A concepção de gênero do discurso}

A noção de gêneros do discurso popularizou-se no Brasil principalmente a partir da publicação dos Parâmetros Curriculares Nacionais (PCN) pelo Ministério da Educação, na segunda metade da década de noventa do século passado. No entanto, há de se convir que essa popularização trouxe, pelo menos, duas implicações: 1) o conceito tornou-se relativamente conhecido - para além do âmbito acadêmico -, o que é, de alguma forma, positivo; 2) o conceito passou a circular sem a devida fundamentação teórica, o que é, em certo sentido, perigoso. No primeiro caso, há uma simplificação de um conceito complexo; no segundo caso, há uma injustiça com a própria teoria, a partir das interpretações muitas vezes equivocadas do que de fato sejam os gêneros discursivos.

$\mathrm{Na}$ tentativa de contribuir para desfazer alguns desses equívocos, ressaltamos a complexidade da noção de gênero, abordada em mais de uma obra do Círculo, mais profundamente em Bakhtin (2003; 2014). Nesse sentido, reiteramos a necessidade de se admitir e até mesmo de se conhecer as múltiplas tendências que existem hoje dentro dos diferentes campos do saber (Linguística Aplicada, Linguística Textual, Linguística Sistêmico-Funcional, Pedagogia, dentre outras), uma vez que, mesmo tendo traços comuns, cada uma dessas abordagens mantém suas especificidades. Não é sem razão que na literatura sobre gêneros encontramos terminologias como "abordagem sociorretórica", "abordagem sociossemiótica", "abordagem sociodiscursiva" e assim por diante. A despeito disso, todas essas tendências têm um viés social e, em maior ou menor proporção, reconhecem e legitimam a guinada dada pelo Círculo de Bakhtin, quando se trata de discutir gêneros do discurso.

Um outro equívoco que gostaríamos de desfazer diz respeito à origem do conceito. Embora isso nos pareça relativamente contraditório - pois, numa perspectiva bakhtiniana, o sujeito não é um "Adão bíblico", ou seja, ele nunca é fonte do seu dizer, visto que sempre terá as vozes dos outros ecoando junto à sua -, o conceito de gênero surge na Antiguidade Clássica, dentro dos estudos retóricos e literários. A falta de base teórica por parte de muitos tem levado a crer que o conceito de gênero foi cunhado pelo 
Círculo, quando na verdade trata-se de uma categoria milenar que, pelo menos no mundo ocidental, é tributada aos gregos. Contudo, é com o filósofo soviético que a ideia de gêneros do discurso é ressignificada, quando ele os reconhece em sua relação com as múltiplas esferas da atividade humana, ultrapassando a díade Retórica-Literatura (aliás, dois domínios que requerem um uso bastante singular e intelectual da palavra) e, inclusive, lançando um olhar para os gêneros do cotidiano (quer orais, quer escritos). No nosso ponto de vista, é a partir dos estudos do Círculo também que os gêneros deixam de ser apenas um princípio de classificação apartado da vida social e ganham mais força pela sua maleabilidade do que pela sua padronização.

A virada proporcionada pelo Círculo de Bakhtin (2003) é sintetizada no "pequeno grande" conceito de gêneros do discurso como tipos relativamente estáveis de enunciados. A nosso ver, dentro desse conceito, pelos menos três categorias merecem aqui ser explicadas: 1) a noção de tipo; 2) a estabilidade relativa e 3) a ideia de enunciado.

Em primeiro lugar, urge enfatizar que a ideia de tipo proposta por Bakhtin aponta para um princípio classificatório, mas não se esgota apenas nisso. Sob esse ponto de vista, os gêneros são vistos como acontecimentos prototípicos, rotinizados, o que nos permite compreendê-los como eventos tipificados. Entretanto, essa tipificação é de natureza social, pois, como vimos, os gêneros emergem de necessidades comunicativas ligadas às inúmeras atividades humanas nas múltiplas instâncias da vida em sociedade. Alertamos ainda para o fato de não se confundir a noção bakhtiniana de tipo de enunciado com a noção de tipos ou sequências textuais (narração, descrição, argumentação, exposição, injunção), uma categoria cunhada pela linguística textualdiscursiva que se refere a um outro fenômeno.

Em segundo lugar, a ideia de estabilidade relativa dos gêneros proposta por Bakhtin dialoga com a visão de língua/linguagem do Círculo, a qual se situa no entrecruzamento das forças centrípetas e centrífugas. Em outros termos, gêneros são convencionados e, simultaneamente, apresentam variações, tendência à inovação. Diante disso, propomos que os gêneros do discurso possam ser localizados num continuum, conforme ilustra a figura abaixo.

Fig. 1 - Equilíbrio instável dos gêneros do discurso

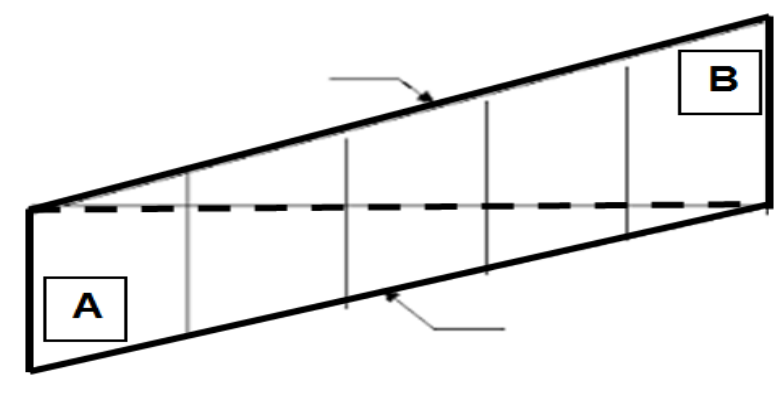


Fonte: Acervo da pesquisa

No polo $\mathrm{A}$, temos os gêneros cujas prototipicidades são mais previsíveis, dada à sua natureza mais padronizada, tais como: diploma, passaporte, boletim de ocorrência, requerimento, memorando, cheque, bilhete de passagem, receita culinária, bula, nota fiscal, mesa-redonda, defesa de tese, relatório, resumo acadêmico, dentre muitos outros. No polo $B$, temos aqueles gêneros que se caracterizam mais pela sua instabilidade e imprevisibilidade, quais sejam: a crônica, o poema (e os textos literários em geral), a conversa cotidiana, a propaganda, a carta pessoal, o e-mail, o chat, o remix, o comentário em sites da internet e inúmeros outros.

Não obstante isso, a linha pontilhada permite-nos compreender que essa polarização dos gêneros do discurso não é dicotômica, mas sim dialógica. Isso nos permite concluir que mesmo os gêneros mais "engessados" podem variar, tal como fizera Graciliano Ramos, ao escrever um relatório administrativo de forma poética, evidenciando, mais uma vez, que as esferas discursivas são tênues e dialógicas e que os gêneros do discurso, de fato, situam-se num constante equilíbrio instável. Por outro lado, os gêneros mais "criativos", podem, em outras circunstâncias, tornarem-se mais formatados. Se tomarmos o poema como exemplo, notamos que ao lado do poema romântico e modernista (de verso livre e branco), do poema concretista e do poema dadaísta - que se tornaram mais "livres" ainda -, temos a existência do soneto, que tem atravessado os tempos com toda sua vivacidade e rigoroso padrão formal.

Em terceiro lugar, o conceito de enunciado proposto pelo Círculo de Bakhtin merece uma atenção especial, uma vez que não deve ser confundido com a ideia de enunciado em outras correntes teóricas, as quais o abordam num plano predominantemente linguístico, chegando até mesmo a usá-lo como sinônimo de frase. No dizer do filósofo russo:

O enunciado existente, surgido de maneira significativa num determinado momento social e histórico, não pode deixar de tocar os milhares de fios ideológicos existentes, tecidos pela consciência ideológica em torno de um dado objeto de enunciação, não pode

Revista Leitura V.1 no 55 - jan/jun 2015 - Número temático: Estudos em perspectivas 
deixar de ser participante ativo do diálogo social. Ele também surge desse diálogo como seu prolongamento, como sua réplica, e não sabe de que lado ele se aproxima desse objeto (BAKHTIN, 2014, p. 86).

Para o Círculo, portanto, o enunciado é histórico, social, ideológico e dialógico, o que nos leva a concluir que ele deve ser visto como acontecimento, como evento único e irrepetível, ou seja, como discurso engendrado numa situação social de interação, cujas características primordiais são a alternância dos sujeitos do discurso, a expressividade e a conclusividade. Em suma, sob a ótica bakhtiniana, os gêneros são tipificações sociais desses enunciados, isto é, são formas de discurso.

Considerando que os gêneros preexistem ao sujeito e que o sujeito não é adâmico, a questão que se coloca é saber de onde vêm os gêneros. Respondendo a esse questionamento, Todorov (1981, p. 48) sustenta que os gêneros "vêm simplesmente de outros géneros. Um novo género é sempre a transformação de um ou de vários géneros antigos: por inversão, por deslocamento, por combinação.” De fato, Bakhtin (2003) já dizia que existem gêneros primários e gêneros secundários; enquanto os primeiros são os gêneros mais simples, os segundos são os mais elaborados (independentemente de serem orais ou escritos). Contudo, essa classificação proposta pelo filósofo russo não é dicotômica, mas dialógica. Dito de outra maneira, os gêneros secundários (romance, por exemplo) aglutinam, reelaboram e intercalam os primários (carta, conversa cotidiana, relato, diário etc.). Nessa linha, Bakhtin (2014) destaca o plurilinguismo dialogizado no romance, a partir dos chamados gêneros intercalados (sejam literários, sejam extraliterários).

Outro aspecto postulado por Bakhtin (2003) concerne aos elementos constitutivos dos gêneros, quais sejam: a construção composicional, o conteúdo temático e o estilo. Com efeito, a construção composicional diz respeito à forma do gênero, embora esta não deva ser desvinculada da sua função social; na verdade, trata-se de uma composição que assegure a prototipicidade do gênero e a sua aceitação na esfera em que circula. $\mathrm{O}$ conteúdo temático refere-se não só ao tópico tratado, mas também à finalidade que o gênero se presta a desempenhar, já que todo dizer se faz por algum propósito, motivado pela intenção discursiva do sujeito e pela situação de interação. $O$ estilo relaciona-se com os aspectos de ordem linguística, sejam gramaticais, sejam lexicais. Todavia, convém ressaltar que esses três elementos - a forma composicional, o 
conteúdo temático e o estilo - estão indissoluvelmente imbricados no todo do enunciado, por isso devem ser analisados de forma integrada (BAKHTIN, 2003).

\section{Metodologia}

A metodologia do trabalho parte da análise de corpus, constituído por um exemplar autêntico do gênero memorando, colhido numa instituição federal de ensino, pesquisa e extensão, em 2014. O exemplar (que não está em anexo por falta de espaço) partiu da pró-reitoria de extensão dessa entidade educacional e foi enviado aos seus respectivos servidores, via e-mail institucional, com o objetivo de solicitar informações (conforme veremos mais adiante). As análises são de cunho interpretativo, visto que se inserem no paradigma da pesquisa qualitativa, realizadas por meio das categorias discutidas na fundamentação teórica deste artigo.

\section{Análise dos dados}

Conscientes do risco de fazer uma análise de gênero a partir de apenas um exemplar (devido ao pouco espaço de que dispomos), propomos segmentá-la em dois níveis: 1) uma análise dos aspectos enunciativo-discursivos do gênero memorando, focando principalmente sua dimensão social e 2) uma análise de cunho verbal e composicional, observando traços linguísticos e lexicais que se manifestam no enunciado analisado.

\section{Aspectos enunciativo-discursivos do gênero memorando}

Do ponto de vista social, que envolve a enunciação/o discurso, uma primeira observação a ser feita diz respeito à relação entre o gênero memorando e a esfera discursiva em que circula, ou seja, a instância administrativa/burocrática. A bem da verdade, memorandos existem porque existem necessidades comunicativas específicas entre os diversos setores que constituem uma determinada instituição, seja ela pública ou privada. Ademais, trata-se de uma forma de interlocução que prima pelo controle e pelo registro escrito daquilo que se enunciou, visto que, como diz o provérbio latino, 
verba volant, escripta manent ${ }^{l}$. Logo, não se trata apenas de uma mera "comunicação interna" ou de um "bilhete formal" fácil de ser reproduzido a partir de um modelo pronto, mas de um gênero complexo como qualquer outro, no que tange ao seu funcionamento discursivo.

Numa perspectiva dialógica, gêneros são produzidos para possibilitar a interação entre interlocutores, que se alternam na condição de falante/escrevente ou de ouvinte/leitor, ocupando papéis sociais determinados, com vistas a finalidades específicas. Assim sendo, o memorando emerge de uma situação de produção que vai além da "vontade discursiva" ou do "intuito discursivo" de um sujeito. Ele é uma prova cabal de que os nossos dizeres são povoados das vozes dos outros. Quem assina o memorando muitas vezes nem o redige, porque dispõe de um profissional que se obriga a fazer isso - uma chefe de gabinete, por exemplo, redige o memorando para o seu superior hierárquico validá-lo e assiná-lo. Além do mais, o sujeito que se responsabiliza pelo texto (discurso) do memorando, o faz em nome de uma voz institucional (como é o caso do/da pró-reitor/a no exemplar analisado). Portanto, dialogicamente, o que podemos afirmar é que o memorando contém a assinatura de alguém responsável por aquele discurso, porém esse alguém, discursivamente, jamais esteve sozinho.

Como a comunicação discursiva é dialógica por excelência, se se produzem memorandos é porque certamente eles precisam ser lidos por alguém que age socialmente; daí dizermos que no outro polo está o leitor, um sujeito ativo, que responde até mesmo com o seu silêncio, que também é ideológico. No caso em análise, o próprio gênero já dispõe de um campo de endereçamento, onde se lê "Aos Diretores Gerais dos Campi", com cópia para as "Direções/Coordenações de Extensão dos Campi”. O que merece ser destacado é que, do ponto de vista bakhtiniano, essa interlocução não para por aqui. Os leitores do memorando responderão ativamente (mesmo que seja uma resposta retardada) ao que está sendo solicitado, de diferentes maneiras, até mesmo podendo ignorá-lo, o que, a nosso ver, não deixa de ser uma resposta ativa.

Nessa perspectiva social, há se considerar a dimensão cronotópica do gênero memorando, pois a relação espaço-tempo mantém uma simbiose, de maneira tal que o memorando configura-se como uma comunicação interdepartamental, minuciosamente controlada por meio de uma sequência numérica, datada, que funciona como

\footnotetext{
1 “As palavras voam, os escritos permanecem", em tradução livre.

Revista Leitura V.1 no 55 - jan/jun 2015 - Número temático: Estudos em perspectivas dialógicas. Análise de gênero discursivo na perspectiva dialógica do Círculo de Bakhtin: subsídios teóricos e aplicados. Valfrido da Silva Nunes e Maria Inez Matoso Silveira. - p. 129 - 144.
} 
mecanismo de controle e de permanência das relações de forças no interior das instituições. Memorandos não são papéis apenas, são registros de como a escrita organiza as práticas sociais no mundo do trabalho, mais especificamente no seu campo predominante de existência - a esfera burocrática -, ao longo dos tempos.

Em termos de circulação, o memorando depende de um suporte típico: o papel timbrado, uma vez que se trata de um gênero institucionalizado. $\mathrm{O}$ modo como esse gênero chega até o leitor pode ser impresso ou virtual. No caso em análise, o memorando foi enviado por e-mail institucional, embora se saiba que a via original certamente foi impressa e arquivada, pois é praxe nas instituições públicas haver pastas designadas exatamente para essa função, ou seja, guardar "memorandos enviados" e "memorandos recebidos". O que chama a atenção é que o suporte tem uma implicação discursiva na produção do gênero, visto que a presença do brasão da república, por exemplo, tem a função de legitimar o caráter institucional do gênero, que é reforçado pela hierarquia das instituições que se agrupam na mesma esfera, a saber: "Ministério da Educação", "Secretaria de Educação Profissional e Tecnológica" e assim por diante. Assim sendo, o suporte constitui-se como uma força centrípeta que, a despeito das dispersões, também assegura a prototipicidade do gênero. A propósito, segundo Zozzoli (2012), a tendência hoje é analisar a inter-relação entre gêneros, textos e suportes (vetores) em torno de um motivo (tema), o que dá uma dimensão mais autêntica do funcionamento dos gêneros discursivos no mundo da vida.

Isso posto, convém sublinhar que, no momento da enunciação, a situação real de interação é fundamental para motivar a escolha do/s gênero/s que será/serão produzido/s, dentro da esfera discursiva a partir da qual o sujeito dialoga. Voloshinov \& Bakhtin (1976, p. 4-5) já insistiam na necessidade de um olhar que exorbitasse o verbal, ao dizer que no mundo da vida "o discurso verbal é claramente não autossuficiente. Ele nasce de uma situação pragmática extraverbal e mantém a conexão mais próxima possível com esta situação. Além disso, tal discurso é diretamente vinculado à vida em si e não pode ser divorciado dela sem perder sua significação." Com efeito, a produção do memorando que analisamos surge de uma situação real motivada pelo não cumprimento de prazos por parte de coordenadores de projetos e bolsistas junto à próreitoria de extensão, os quais deveriam apresentar os resultados de seus trabalhos na "II Mostra de Extensão” promovida pela instituição. 
É possível perceber no gênero em tela a ligação entre o que está sendo dito com o que já se disse e com aquilo que ainda se vai dizer, o que evidencia os fios dialógicos do discurso na cadeia ininterrupta da comunicação discursiva. Esse movimento retrospectivo e prospectivo é marcado no texto em análise por meio da referência a diálogos anteriores ("Como é de conhecimento de Vossas Senhorias", “vide memorando circular n 058/2014 - PROEXT", “Aproveitamos a oportunidade para lembrar que...") e potenciais diálogos futuros ("gostaríamos de solicitar a Vossas Senhorias a realização de confirmação de participação", "gostaríamos que a confirmação fosse encaminhada (...) até o dia x", "pedimos que a Direção/Coordenação de Extensão do Campus entre em contato com os responsáveis pelo programa ou projeto", "colocamo-nos à disposição para dirimir quaisquer dúvidas”).

\section{Aspectos verbo-composicionais do gênero memorando}

No que diz respeito à forma composicional, o memorando é um gênero que sofre poucas variações, pois se enquadra predominantemente no polo da estabilidade do continuum que propomos neste trabalho. De fato, trata-se de um construto bastante prototípico, em função das recorrências das atividades humanas, cujas restrições são determinadas pela esfera discursiva em que circula. Se observarmos a sua composição, o gênero em tela dialoga com muitos outros do âmbito epistolar, pois ele reelabora gêneros como a carta pessoal e o bilhete, além de se configurar como uma espécie de "conversa por escrito", o que nos remete, em alguma proporção, à conversa cotidiana. Em termos bakhtinianos, o memorando é um gênero mais elaborado (secundário) que intercala e transmuta gêneros da cotidianidade (primários).

No que concerne aos conteúdos temáticos veiculados no gênero memorando, podemos afirmar que são bastante heterogêneos. Aliás, nem mesmo somente um exemplar está a serviço de um único propósito. O que é possível prever é que o assunto a ser tratado circunscreve-se ao âmbito profissional, institucional; no entanto, não se tem como mensurar todas as temáticas tratadas por todos os memorandos. Lembremonos, inclusive, de que também existem assuntos sigilosos, os quais são veiculados respeitando-se os trâmites legais. No exemplar foco de nossa análise, constatamos que o memorando foi gerado a partir de mais de um propósito comunicativo, dentre eles: a) reiterar que o prazo de vencimento da entrega dos documentos solicitados pela Pró- 
Reitoria de Extensão (PROEXT) expirou; b) apresentar dados ("planilha") que justifiquem o não cumprimento de prazos por parte de alguns coordenadores de projetos e bolsistas; c) isentar a PROEXT das consequências advindas da não entrega dos documentos no prazo solicitado; d) solicitar a confirmação de participação na Mostra de Extensão da instituição; e) pedir o apoio dos campi na resolução do problema; f) informar onde acontecerá a referia Mostra; g) descrever as atividades que comporão a Mostra, dentre outros.

Diante disso, resta-nos ressaltar que a dimensão dada por apenas um exemplar do gênero evidencia o quão diversos são os conteúdos temáticos abordados pelo memorando. Longe de ser apenas uma "comunicação interna" - segundo muitos manuais da chamada redação oficial - tampouco um "bilhete formal", o memorando reflete e refrata os usos que se fazem da língua/linguagem numa intrincada relação com as práticas sociais, dentro da esfera burocrática estatal, funcionando como um construto complexo que pode e deve ser analisado em sua dimensão ideológico-axiológica.

No que se refere ao estilo verbal do gênero em estudo, parece-nos serem mais evidentes as marcas da formalidade, da tentativa de impessoalizar o discurso e da busca pela objetividade. Em relação à formalidade, enfatizamos que esse nível linguístico é típico do gênero, devido às relações hierárquicas estabelecidas dentro das instituições; aliás, trata-se de um gênero oriundo de relações profissionais, entre interlocutores que têm pouca ou quase nenhuma intimidade. Esse registro linguístico manifesta-se no gênero analisado por meio dos pronomes de tratamento ("Vossas Senhorias"), da adequação à norma padrão escrita da língua portuguesa (a concordância, a colocação pronominal, a regência, a ortografia, a pontuação etc.), da fórmula de fechamento do texto (“Atenciosamente”) e do próprio léxico, pois as palavras são signos ideológicos por excelência (BAKHTIN, 2009). O termo "vide" (uma palavra latina que serve para remeter a outro texto ${ }^{2}$ existente) também justifica o grau de formalidade do texto, visto que não é uma palavra comum na escrita do dia a dia, tampouco na oralidade. A presença da modalização, por meio de expressões como "gostaríamos de solicitar" e "gostaríamos que a confirmação fosse encaminhada" mostra a preocupação em suavizar o impacto da cobrança, o que contribui para assegurar o grau de formalidade típico deste gênero.

\footnotetext{
${ }^{2}$ A palavra texto está sendo empregada neste trabalho numa acepção discursiva, conforme defende Bakhtin (2003), mais especificamente no seu manuscrito intitulado "O problema do texto na linguística, na filologia e em outras ciências humanas".

Revista Leitura V.1 no 55 - jan/jun 2015 - Número temático: Estudos em perspectivas dialógicas. Análise de gênero discursivo na perspectiva dialógica do Círculo de Bakhtin: subsídios teóricos e aplicados. Valfrido da Silva Nunes e Maria Inez Matoso Silveira. - p. $129-144$.
} 
Na concepção bakhtiniana, o sujeito, que não é individualista, sempre trará consigo as vozes dos outros, ou seja, ele será sempre um representante do auditório médio social do qual faz parte (BAKHTIN, 2009). Essa posição corrobora que a questão da impessoalidade do discurso é questionável. Entretanto, na esfera burocrática, como o sujeito representa a voz institucional, torna-se menos propício a ele deixar as suas marcas de subjetividade, tal como elas são recorrentes nos textos literários de maneira geral. Dessa forma, o que vemos no memorando em análise é uma predominância da primeira pessoa do plural. Nessa forma verbal, à medida que o sujeito que se responsabiliza pelo texto inclui-se nele (assinando-o), simultaneamente ele não está sozinho, como se houvesse um compartilhamento de responsabilidades pelo dito ("realizamos", “apresentamos", “aproveitamos", "agradecemos", "colocamo-nos", dentre outros).

A busca por uma suposta objetividade também se mostra pelo fenômeno da referenciação, quando se opta por expressões mais abstratas, ao invés de se mostrarem os agentes de fato, o que é ideológico. $\mathrm{Na}$ passagem "alguns programas e projetos cadastrados não apresentaram os relatórios parciais", vemos que não há referência às pessoas que estão em débito com a instituição, mas isso é feito de forma generalizada. Por outro lado, em “a PROEXT não se responsabilizará pela confecção dos banners", mais uma vez não há referência aos sujeitos de fato, mas ao órgão vinculado à instituição, no caso, a pró-reitoria, o que torna o discurso um tanto mais abstrato e genérico. Em resumo, o que não se pode ignorar é a natureza dialógica entre os aspectos sociais e verbais do gênero, na sua intrínseca relação com a esfera de atividade em que circula, o que ratifica o caráter vivo da língua/linguagem.

\section{Considerações finais}

O presente trabalho fez um breve estudo sobre o gênero memorando na esfera burocrática estatal, sob a perspectiva dialógica do discurso. Os principais achados dizem respeito à natureza complexa do memorando, visto que, a despeito de que se tem afirmado na chamada redação oficial, o referido gênero não é um simples "bilhete formal". Por outro lado, as análises ratificaram a necessidade se olhar para o gênero considerando tanto os aspectos sociais quanto os de ordem verbal, os quais dialogam entre si, movidos pelas forças que emanam da esfera discursiva na qual os gêneros se 
circunscrevem. Aspectos como as relações de força no âmbito institucional, a particularidade do suporte, os papéis dos interlocutores, os conteúdos temáticos ligados à vida da instituição, a tendência à padronização, a formalidade e a busca pela objetividade são pontos abordados na nossa interpretação. Julgamos fecundo que se façam, posteriormente, análises que levem em consideração mais de um exemplar do gênero, sua inter-relação com demais gêneros da esfera, bem como outros instrumentos de pesquisa que possam assegurar um olhar mais autêntico sobre o funcionamento do gênero memorando na sua instância típica de circulação.

\section{Referências}

BAKHTIN, M. Questões de literatura e estética: a teoria do romance. 7. ed. São Paulo: Hucitec, 2014.

BAKHTIN, M. Problemas da poética de Dostoiévski. 5. ed. Rio de Janeiro: Forense Universitária, 2013.

BAKHTIN, M.; VOLOCHÍNOV. Marxismo e filosofia da linguagem: problemas fundamentais do método sociológico na ciência da linguagem. 13. ed. São Paulo: Hucitec, 2009.

BAKHTIN, M. Estética da criação verbal. 4. ed. São Paulo: Martins Fontes, 2003.

NUNES, V. S. O gênero carta do leitor no Jornal do Commercio de Pernambuco: uma abordagem sociorretórica. 2012. 236f. Dissertação (Mestrado em Letras e Linguística) - Universidade Federal de Alagoas, Maceió, 2012.

NUNES, V. S. Saussure e Bakhtin: duas visões, um mesmo objeto. In: ENCONTRO DA PÓS-GRADUAÇÃO EM LETRAS, 3., 2010, São Cristóvão. Anais do III ENPOLE: deslocamentos culturais. São Cristóvão, SE: NPGL/UFS, 2010, p. 18081823. CD-ROM.

TODOROV, T. Os géneros do discurso. Lisboa: Edições 70, 1981.

VOLOSHINOV, V. N.; BAKHTIN, M. M. Discurso na vida e discurso na arte: sobre poética sociológica. Trad. de Carlos Alberto Faraco \& Cristóvão Tezza [para fins didáticos]. Versão da língua inglesa de I. R. Titunik, a partir do original russo, 1976.

ZOZZOLI, R. M. D. A articulação discursiva entre gêneros, textos e suportes, numa perspectiva dialógica em torno do tema da defesa da diferença. Eutomia, Recife, v. 5, n. 9, p. 343-358, jul./2012. Disponível em:

<http://www.revistaeutomia.com.br/v2/category/edicao-9-ano-v-jul2012/linguistica/> Acesso em: 18 jan. 2015.

Revista Leitura V.1 no 55 - jan/jun 2015 - Número temático: Estudos em perspectivas dialógicas. Análise de gênero discursivo na perspectiva dialógica do Círculo de Bakhtin: subsídios teóricos e aplicados. Valfrido da Silva Nunes e Maria Inez Matoso Silveira. - p. $129-144$. 